\title{
The endothelial saga: the past, the present, the future
}

\author{
Dragomir N. Serban • Bernd Nilius • Paul M. Vanhoutte
}

6 Received: 11 February 2010 / Accepted: 13 February 2010

7 (C) Springer-Verlag 2010

\begin{abstract}
Endothelium-dependent changes in vasomotor tone, whether evoked by vasoactive agents or physical forces, are recognized as essential for the local hemodynamic control in various normal and pathological circumstances. They are based on a complex signaling network within the vascular wall. In recent years, substantial efforts have been made to analyze how such signals are generated and used in the endothelium-dependent control of vascular smooth muscle. The underlying mechanisms vary with species, age, sex, hormonal status, vascular bed studied, caliber of the blood vessels, triggering stimuli, pre-existing vascular tone, oxidative stress, and pathology. Such aspects and many others will be addressed specifically by the authors contributing to this volume.
\end{abstract}

Keywords Endothelium · Nitric oxide $\cdot \mathrm{EDHF} \cdot \mathrm{K}_{\mathrm{Ca}} \cdot \mathrm{TRP}$. Oxidative stress

\footnotetext{
D. N. Serban

Laboratory of Cell Physiology and Pharmacology,

Center for Study and Therapy of Pain,

"Gr. T. Popa" University of Medicine and Pharmacy,

16 Universitatii Str.,

700115 Iasi, Romania

\section{B. Nilius}

Laboratory of Ion Channel Research,

Department of Molecular Cell Biology, KU Leuven,

Campus Gasthuisberg, O\&N 1, Herestraat 49 bus 802,

3000 Leuven, Belgium

P. M. Vanhoutte $(\bowtie)$

Department of Pharmacology and Pharmacy,

Li Ka Shing Faculty of Medicine, University of Hong Kong,

Laboratory Block 2/F, 21 Sassoon Road, Pokfulam,

Hong Kong, China

e-mail: vanhoutt@hku.hk
}

\section{The endothelial saga: the past}

The endothelial saga started with Robert Furchgott [18, 61], who demonstrated that endothelial cells play an essential role in the relaxation evoked by acetylcholine in isolated arteries, which is mediated by activation of endothelial muscarinic receptors. His simple pharmacological experiments have revolutionized not only vascular pharmacology and physiology but science in general, as they lead to the discovery of the role of nitric oxide (NO) in biology [61]. Using "sandwich" bioassay preparations (a layering of arterial strips with and without endothelium whereby the contractile responses are measured only in the strip without endothelium), he demonstrated that the endotheliumdependence of the response to acetylcholine is due to the diffusion of a vasodilator substance from the endothelial cells to the vascular smooth muscle cells [18]. Having ruled out prostacyclin, which is produced by endothelial cells [41], he called the unknown mediator "endothelium-derived relaxing factor" (EDRF). The existence of endotheliumdependent responses was rapidly confirmed in different laboratories around the world [see 37]. More sophisticated superfusion-bioassay systems permitted to apply pharmacological inhibitors to either the endothelial cells or the effector vascular smooth muscle cells [e.g., 50]. The biological half-life of EDRF was found to be disappointingly brief (in the order of seconds), making identification by conventional chemical techniques impossible. Early pharmacological studies indicated that endothelial cells can generate several other signals leading to endotheliumdependent relaxations [8]. The latter multiple signals (Fig. 1) eventually became known as "endothelium-derived hyperpolarizing factor(s)" (EDHF), which play a prominent role in smaller arteries and resistance vessels [7, 15]. In addition, it soon became obvious that, in veins [9], and in 


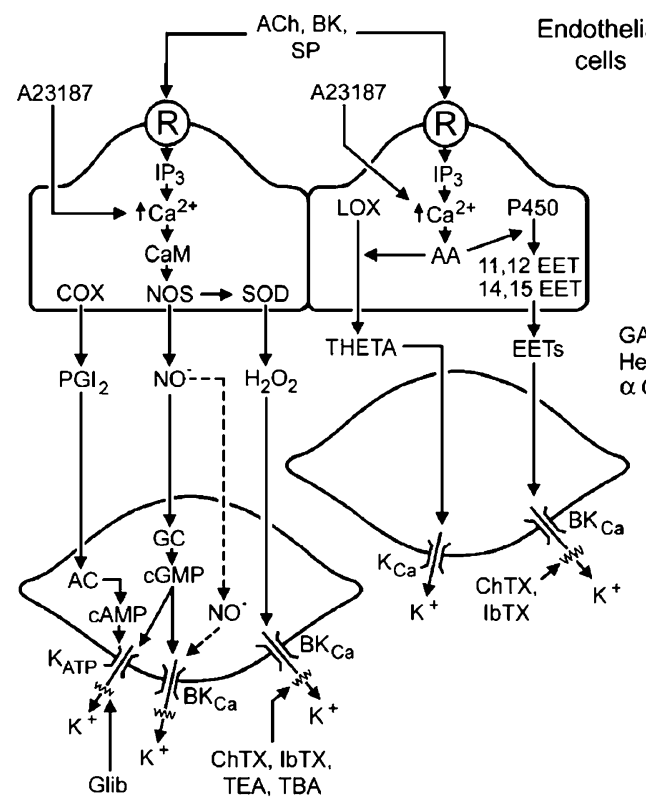

Fig. 1 EDRFs in 2009. Substances such as acetylcholine $(A C h)$, bradykinin $(B K)$, and substance $\mathrm{P}(S P)$, through the activation of $\mathrm{M}_{3}$ muscarinic, $\mathrm{B}_{2}$-bradykinin, and $\mathrm{NK}_{1}$-neuroknin receptor subtypes, respectively, and agents that increase intracellular calcium, such as the calcium ionophore A23187, release EDHFs. CaM calmodulin, COX cyclooxygenase, EET epoxyeicosatrienoic acid, $I P_{3}$ inositol trisphosphate, $G C$ guanylate cyclase, $N A P E N$-acylphosphaticylethanolamine, Hyperpol hyperpolarization, $\mathrm{NOS} \mathrm{NO}$ synthase, $\mathrm{O}_{2}^{-}$superoxide anions, $\mathrm{PGI}_{2}$ prostacyclin, $\mathrm{P} 450$ cytochrome $\mathrm{P} 450$ monooxygenase, $R$ receptor, $X$ putative EDHF synthase. SR141716 is an antagonist of the cannabinoid receptor subtype $\mathrm{CB}_{1}$. Glibenclamide $(G l i b)$ is a selective inhibitor of ATP-sensitive potassium channels $\left(K_{A T P}\right)$. Tetraethylammonium (TEA) and tetrabutylammonium $(T B A)$ are

arteries as well [36], the endothelium produces "endothelium-derived contracting factors" (EDCF), which add to the difficulty of analyzing endothelium-dependent responses $[17,37,64]$. More physiological stimuli than acetylcholine [including physical forces (increases in shear stress), circulating hormones (catecholamines, vasopressin,), platelet products (serotonin, adenosine diphosphate), autacoids (histamine, bradykinin), prostaglandin $\mathrm{E}_{4}$, and thrombin] were shown to cause endothelium-dependent relaxations [37, 63]. Of those more physiological stimuli, increases in shear stress [51] explain the endothelium-dependency of flow-mediated vasodilatation, a response that allows the most accurate assessment of endothelial function in humans. Research in the field was fostered by the fact that endotheliumdependent relaxations are reduced under a number of pathological conditions, including myocardial infarction [32] and hypertension [31], which lead to the current conviction that endothelial dysfunction precedes, or at least accompanies, vascular disease and predicts the occurrence of cardiovascular events [39,63].

It soon appeared that EDRF, whatever its nature, stimulated soluble guanylyl cyclase in vascular smooth

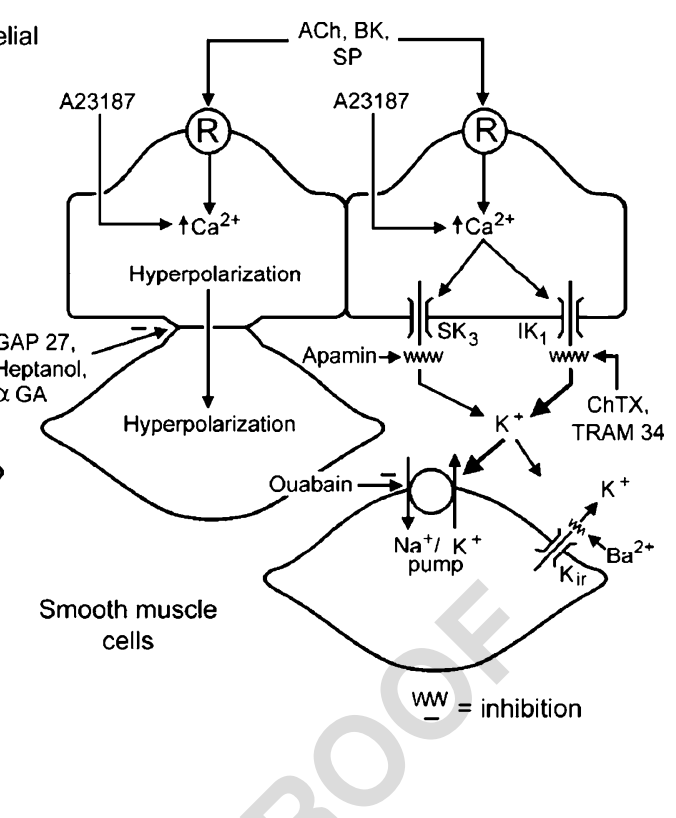

nonspecific inhibitors of potassium channels when used at high concentrations $(>5 \mathrm{mM})$, while at lower concentrations (1-3 mM), these drugs are selective for calcium-activated potassium channels $\left(K_{C a}\right)$. Iberiotoxin $(I B X)$ is a specific inhibitor of large conductance $\mathrm{K}_{\mathrm{Ca}}\left(B K_{C a}\right)$. Charybdotoxin $(C T X)$ is an inhibitor of $\mathrm{BK}_{\mathrm{Ca}}$, intermediate conductance $\mathrm{K}_{\mathrm{Ca}}\left(I K_{C a}\right)$, and voltage-dependent potassium channels. Apamin is a specific inhibitor of small conductance $\mathrm{K}_{\mathrm{Ca}}$ $\left(S K_{\mathrm{Ca}}\right)$. Barium $\left(\mathrm{Ba}^{2+}\right)$, in the micromolar range, is a specific inhibitor of the inward rectifier potassium channel $\left(K_{i r}\right)$. GAP 27 is an 11amino acid peptide possessing conserved sequence homology to a portion of the second extracellular loop of connexin. $18 \alpha-$ glycyrrhetinic acid $(\alpha G A)$, and heptanol are gap junction uncouplers (from Vanhoutte et al., 2009. By permission)

muscle [28]. Soluble guanylyl cyclase catalyzes the formation of cyclic guanosine monophosphate (cyclic GMP), which in turn initiates relaxation. The demonstration followed that under superfusion-bioassay conditions superoxide anions scavenge EDRF [21, 52]. Based on the earlier observation that nitric oxide (NO) activates soluble guanylyl cyclase and is scavenged by superoxide anions [42] and on his own work with acidified nitrite, Robert Furchgott proposed in 1986 that his EDRF is NO [19]. Louis Ignarro had reached the same conclusion [27]. One year later, Salvador Moncada and his colleagues demonstrated, using a chemiluminescence technique, that, when cultured endothelial cells are stimulated with bradykinin, they indeed release NO [45]. The biology of NO was born. One crucial finding was that macrophages and endothelial cells transform the semi-essential amino acid L-arginine into NO and citrulline, and then inhibitors of the responsible enzymatic activity were discovered [24, 46, 48]. The access to inhibitors of nitric oxide synthase (NOS) permitted the exploration of the physiological role of NO in isolated tissues and organs, and in the intact organism. The fact that they augment arterial blood pressure in vivo 
103 [49] implied a role for NO in cardiovascular homeostasis.

104 The use of NOS inhibitors in vivo rapidly lead to the 105 conclusion that NO not only is a key player in vasomotor 106 control but it affects almost every bodily function. The next 107 breakthrough came when Salomon Snyder and his group 108 isolated NOS from the brain [e.g., 6]. We now know that 109 there are three isoforms of the enzyme: neuronal NOS 110 (nNOS, NOS 1), inducible NOS (iNOS, NOS 2), and 111 endothelial NOS (eNOS, NOS 3). Paul Huang and

colleagues genetically engineered mice with deletion of the eNOS gene [25]. These animals have an increased arterial blood pressure, illustrating the role of $\mathrm{NO}$ in the control of cardiovascular homeostasis.

\section{The endothelial saga: the present}

The advent of genetically modified animals and of inhibitors of NOS permits the systematic exploration of the role of NO in vascular health and disease, considerably increasing our knowledge (Fig. 2). In a given blood vessel, the level of activity of eNOS and the amounts of endothelium-derived NO released are not constant. They can be upregulated by chronic increases in shear stress (exercise), hormones (estrogens), and diet ( $\omega_{3}$-unsaturated fatty acids or polyphenols of red wine, green tea, and dark chocolate). The endothelial production of NO is reduced by high glucose (diabetes) and increased oxidative stress (hypertension) [see 3, 63]. NO not only affects the tone of vascular smooth muscle, but also inhibits platelet aggregation, in synergy with endothelium-derived prostacyclin [47], and the growth of the media [55]. It reduces the endothelial production of endothelin-1 [62] and of cyclooxygenase-derived EDCF [14]. NO inhibits the expression of endothelial adhesion molecules and, thus, the adhesion of platelets and white blood cells [47, 63]. It modulates angiogenesis $[3,68]$. The signaling cascade, in particular, the role of Akt, in the phosphorylation that leads to activation of eNOS is unraveled [3, 16, 29, 33]. The original concept that the eNOS is a strictly $\mathrm{Ca}^{2+}$-dependent enzyme, and, thus, that endothelium-dependent relaxations rely entirely on an increase in intracellular $\mathrm{Ca}^{2+}$-concentration, has been challenged $[3,16]$. Moreover, in vivo responses to acetylcholine in arterioles consist of two phases: (a) a rapidly conducted vasodilatation initiated by a local rise in endothelial $\mathrm{Ca}^{2+}$ but independent of endothelial $\mathrm{Ca}^{2+}$-signaling at remote sites and (b) a slower complementary dilatation associated with a $\mathrm{Ca}^{2+}$-wave that propagates along the endothelium [57]. In the mouse aorta, calcium-imaging shows that only some clusters of endothelial cells respond to acetylcholine, which represent only one third of the total number of cells, but this is enough for endothelium-dependent relaxation [4]. The importance of

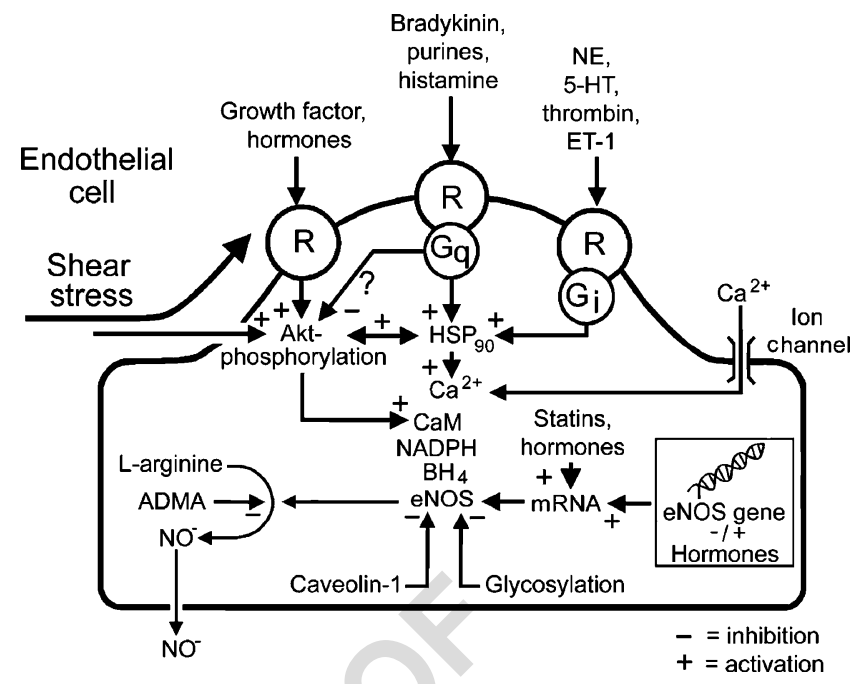

Fig. 2 Possible mechanisms by which production of nitric oxide is regulated in endothelial cells. Nitric oxide is produced through enzymatic conversion of L-arginine by NOS (endothelial or type III, $e N O S$ ). The transcription of this enzyme is regulated genomically by hormones and growth factors. Stability of eNOS mRNA is modulated by statins and hormones. eNOS enzyme activity requires calcium, calmodulin, nicotinamide adenine dinucleotide phosphate $(N A D P H)$, and 5, 6, 7, 8-tetra-hydrobiopterine $\left(\mathrm{BH}_{4}\right)$. Enzyme activity is regulated by complexing to these proteins in microdomains of the endothelial cell. Association with this complex of heat shock protein $90\left(H S P_{90}\right)$ increases enzyme activity. Stimulation of specific receptors on the endothelial surface $(R)$ complexed with guanine nucleotide regulatory proteins, which are sensitive to pertussis toxin $\left(G_{i}\right)$ or insensitive to pertussis toxin $\left(G_{q}\right)$, activate intracellular pathways that modulate eNOS activity posttranslationally through heat shock protein 90 or Akt-phosphorylation. Association of eNOS with caveolin-1 or glycosylation of the enzyme reduces activity. A metabolite of L-arginine, asymmetric dimethyl arginine (ADMA) decreases production of the nitric oxide through competitive binding to eNOS. Thus, this endogenous amine may be a risk factor for the development of cardiovascular disease. Plus signs indicate stimulation, minus signs indicate inhibition, question marks indicate those pathways in which the regulation is unknown (from Vanhoutte et al., 2009. By permission)

the caveolae for the activity of eNOS is now established $[20,40]$. The formation of NO-metabolites constitutes a non-enzymatic source of activators of soluble guanylyl cyclase [38]. Beyond NO itself, derivatives such as nitroxyl (HNO) and nitrosothiols have also emerged as EDRFs and HNO may be as important as NO in rodent small arteries [2]. The binding of NO to superoxide anions, with the formation of peroxynitrite, is a major player in genesis of endothelial dysfunction [23, 30, 58, 67]. The progressive inability of endothelial cells, prematurely aged by the exposure to risk factors, to generate sufficient NO may well be the initial step permitting the inflammatory response that leads to atherosclerosis [see 63]. The most widely used therapeutic agents for the treatment of cardiovascular disease enhance the ability of the endothelial cells to produce NO $[26,59,64]$. 
169 We now appreciate better the importance and the 170 complexity of endothelium-dependent hyperpolarization in 171 the local control of vascular tone [7]. Although EDHF has 172 been considered to be of particular importance in smaller 173 arteries, we have to recognize that its contribution to 174 vasodilatation may be merely transient [22]. Nevertheless, 175 coordinated increases in small artery diameter occur by 176 means of flow-mediated vasodilatation (shear-stress-in177 duced and NO-dependent) combined with the conducted 178 vasodilatation resulting from electrotonic propagation of 179 hyperpolarization in the endothelium [56]. At the level of 180 endothelial protrusions, functional cooperation ensures the 181 EDHF-component of endothelium-dependent vasodilata182 tion, which is mediated by $\mathrm{K}^{+}$released from endothelium 183 and involves endothelial $\mathrm{K}_{\mathrm{Ca}} 2.3$ and $\mathrm{K}_{\mathrm{Ca}} 3.1$, local intersti184 tial $\mathrm{Ca}^{2+}, \mathrm{Ca}^{2+}$-sensing receptors co-localized with $\mathrm{K}_{\mathrm{Ca}} 3.1$ 185 in caveolin-poor regions of endothelial cells, myo186 endothelial gap junctions, and the $\mathrm{Na} / \mathrm{K}$ pump and $\mathrm{K}_{\mathrm{ir}} 2.1$ 187 of the vascular smooth muscle [11]. Experiments in 188 dysgenic mice suggest that $\mathrm{K}_{\mathrm{Ca}} 2.3$ and $\mathrm{K}_{\mathrm{Ca}} 3.1$ have 189 important but different contributions to endothelium190 dependent vasodilatation and, thus, represent novel thera191 peutic targets for the treatment of hypertension [5, 66]. 192 Inositol 1,4,5-endothelial trisphosphate receptors in the 193 endothelial protrusions subserve local $\mathrm{Ca}^{2+}$-release events 194 ("pulsars"), which activate the functionally co-localized $195 \mathrm{~K}_{\mathrm{Ca}} 3.1$ [34]. Activators of the small and intermediate 196 conductance $\mathrm{K}$ channels constitute useful pharmacological 197 tools and potential new drugs for the treatment of 198 hypertension [54].
The $\mathrm{Ca}^{2+}$-dependent component of local vasodilation obviously depends on $\mathrm{Ca}^{2+}$ influx into endothelial cells. One of the most attractive candidate influx pathways has been the store-operated $\mathrm{Ca}^{2+}$ entry (SOC), which could be mediated by transient receptor potential (TRP) channels [see 43 for a critical review]. SOC was indeed identified in endothelium $[1,13]$, but a direct relation to NO production and release is still under evaluation [4]. Non-storeoperated channels seem to play a more important role in regulation of NO release [65]. The involvement of TRPV4-channels in flow-induced endothelium-dependent vasodilatation is now generally accepted [35, see also 44 for a review]; the mechanism requires an active CYP epoxygenase and channel translocation to the cell membrane, where it is associated with caveolin-1. Moreover, the expression of caveolin-1 is required for EDHF-related relaxation, by modulating the membrane location and activity of TRPV4 channels and connexins, which are both implicated at different steps in the EDHF-signaling pathway [53]. The TRPV4 channels of both endothelial and vascular smooth muscle cells are critically involved in endothelium-dependent vasodilatation of mesenteric arteries and in TRPV4-knockout mice the hypertension induced by NOS inhibition is greater than in wild-type animals [12].

\section{The endothelial saga: the future}

Much remains to be learned about the precise regulation of NO release by endothelial cells and also about the consequences of its perturbation within the complex chain of events leading to the vascular dysfunction characteristic of hypertension, diabetes, and atherosclerosis [64]. We still do not completely understand the exact role of EDHF-mediated responses in physiology and pathology, as we are still unable to selectively interfere with them in vivo [7]. We still do not fully comprehend the importance of EDCFs in endothelial dysfunction [60]. Finally, we have to unravel the complex interactions between the different endothelium-derived signals. For example, in diabetic mice, hyperglycemia-induced changes in endothelial function are linked to COX2 and oxidative stress (enhanced NADPH oxidase and decreased SOD expression), uncoupling of eNOS, and changes in its expression and regulation, while EDHF-mediated vasodilatation can be maintained, but with a modified profile [10]. Whatever the future of endothelial research will yield, we should not forget that this extraordinary scientific saga started with the very simple pharmacological experiments of Robert Furchgott [18, 61], whose memory we honor in this special issue.

Acknowledgement This work was supported by grants from the Romanian National Authority for Scientific Research via UEFISCSU and CNCSIS (grant ID_1156/2007-2010 from the program IDEI of plan PNCDI-II), the Belgian Ministry for Science Policy (Interuniversity Attraction Pole IUAP P6/28), the Research Foundation-Flanders (G.0172.03 and G.0565.07), the Research Council of the KU Leuven (GOA 2004/07 and EF/95/010).

The editors initiated this special issue as a result of discussions originating at "Works and Views in Endothelium-Dependent Vasodilation," an international symposium organized by D. N. Serban in May 2009, in Iasi, Romania, which was supported from the mentioned Romanian grant and sponsored by DABMMed.

\section{References}

1. Abdullaev IF, Bisaillon JM, Potier M, Gonzalez JC, Motiani RK, Trebak M (2009) Stim1 and Orail mediate CRAC currents and store-operated calcium entry important for endothelial cell proliferation. Circ Res 103:1289-1299

2. Andrews KL, Irvine JC, Tare M, Apostolopoulos J, Favaloro JL, Triggle CR, Kemp-Harper BK (2009) A role for nitroxyl (HNO) as an endothelium-derived relaxing and hyperpolarizing factor in resistance arteries. Br J Pharmacol 157:540-550

3. Balligand J-L, Feron O, Dessy C (2009) eNOS activation by physical forces: from short-term regulation of contraction to chronic remodeling of cardiovascular tissues. Physiol Rev 80:481-534
225

226

227

228

229

230

231

232

233

234

235

236

237

238

239

240

241

242

243

244

245

246

247

248

249

250

251

252

253

254

255

256

257

258 259 
4. Boittin FX, Gribi F, Serir K, Bény JL (2008) Ca2+-independent PLA2 controls endothelial store-operated $\mathrm{Ca} 2+$ entry and vascular tone in intact aorta. Am J Physiol Heart Circ Physiol 295:H2466$\mathrm{H} 2474$

5. Brähler S, Kaistha A, Schmidt VJ, Wölfle SE, Busch C, Kaistha BP, Kacik M, Hasenau AL, Grgic I, Si H, Bond CT, Adelman JP, Wulff H, de Wit C, Hoyer J, Köhler R (2009) Genetic deficit of SK3 and IK1 channels disrupts the endothelium-derived hyperpolarizing factor vasodilator pathway and causes hypertension. Circulation 119:2323-2332

6. Bredt DS, Snyder SH (1990) Isolation of nitric oxide synthetase, a calmodulin-requiring enzyme. Proc Nat Acad Sci U S A 87:682685

7. Busse R, Edwards G, Félétou M, Fleming I, Vanhoutte PM (2002) EDHF: Bringing the concepts together. Trends Pharmacol Sci 23:374-380

8. De Mey JG, Claeys M, Vanhoutte PM (1982) Endotheliumdependent inhibitory effects of acetylcholine, adenosine triphosphate, thrombin and arachidonic acid in the canine femoral artery. J Pharmacol Exp Ther 222:166-173

9. De Mey JG, Vanhoutte PM (1982) Heterogeneous behavior of the canine arterial and venous wall: importance of the endothelium. Circ Res 51:439-447

10. Ding H, Aljofan M, Triggle CR (2007) Oxidative stress and increased eNOS and NADPH oxidase expression in mouse microvessel endothelial cells. J Cell Physiol 212:682-689

11. Dora KA, Gallagher NT, McNeish A, Garland CJ (2008) Modulation of endothelial cell KCa3.1 channels during endothelium-derived hyperpolarizing factor signaling in mesenteric resistance arteries. Circ Res 102:1247-1255

12. Earley S, Pauyo T, Drapp R, Tavares MJ, Liedtke W, Brayden JE (2009) TRPV4-dependent dilation of peripheral resistance arteries influences arterial pressure. Am J Physiol Heart Circ Physiol. doi:10.1152/ajpheart.00241.2009

13. Fasolato C, Nilius B (1998) Store depletion triggers the calcium release-activated calcium current (ICRAC) in macrovascular endothelial cells: a comparison with Jurkat and embryonic kidney cell lines. Pflügers Arch 436:69-74

14. Feletou M, Tang EH, Vanhoutte PM (2008) Nitric oxide the gatekeeper of endothelial vasomotor control. Front Biosci 13:4198-4217

15. Félétou M, Vanhoutte PM (2006) EDHF: where are we now? Arterioscler Thromb Vasc Biol 26:1215-1225

16. Fleming I, Busse R (2003) Molecular mechanisms involved in the regulation of the endothelial nitric oxide synthase. Am J Physiol Regul Integr Comp Physiol 284:R1-R12

17. Furchgott RF, Vanhoutte PM (1989) Endothelium-derived relaxing and contracting factors. FASEB J 3:2007-2017

18. Furchgott RF, Zawadzki JV (1980) The obligatory role of endothelial cells in the relaxation of arterial smooth muscle by acetylcholine. Nature 299:373-376

19. Furchgott RF (1988) Studies on relaxation of rabbit aorta by sodium nitrite: the basis for the proposal that acid-activable inhibitory factor from bovine retractor penis is inorganic nitrite and the endothelium-derived relaxing factor is nitric oxide. In: Vanhoutte PM (ed) Vasodilatation: vascular smooth muscle peptides, autonomic nerves and endothelium. Raven, New York, pp 401-414

20. Gratton JP, Bernatchez P, Sessa WC (2004) Caveolae and caveolins in the cardiovascular system. Circ Res 94:14081417

21. Gryglewski RJ, Palmer RMJ, Moncada S (1986) Superoxide anion is involved in the breakdown of endothelium-derived vascular relaxing factor. Nature 320:454-456

22. Harrington LS, Carrier MJ, Gallagher N, Gilroy D, Garland CJ, Mitchell JA (2007) Elucidation of the temporal relationship between endothelial-derived NO and EDHF in mesenteric vessels. Am J Physiol Heart Circ Physiol 293:H1682-H1688

23. Heistad DD, Wakisaka Y, Miller J, Chu Y, Pena-Silva R (2009) Novel aspects of oxidative stress in cardiovascular diseases. Circ J 73:201-207

24. Hibbs JB Jr, Taintor RR, Vavrin Z (1987) Macrophage cytotoxicity: role for L-arginine deiminase and imino nitrogen oxidation to nitrite. Science 235:473-476

25. Huang PL, Huang Z, Mashimo H, Bloch KD, Moskowitz MA, Bevan JA, Fishman MC (1995) Hypertension in mice lacking the gene for endothelial nitric oxide synthase. Nature 377:239-242

26. Ignarro LJ (2008) Different pharmacological properties of two enantiomers in a unique $\beta$-blocker, nebivolol. Cardiovasc Ther 26:115-134

27. Ignarro LJ, Byrns RE, Wood KS (1988) Biochemical and pharmacological properties of endothelium- derived relaxing factor and its similarity to nitric oxide radical. In: Vanhoutte PM (ed) Vasodilatation: vascular smooth muscle peptides, autonomic nerves and endothelium. Raven, New York, pp 427-436

28. Ignarro LJ, Harbison RG, Wood KS, Kadowitz PJ (1986) Activation of purified soluble guanylate cyclase by endotheliumderived relaxing factor from intrapulmonary artery and vein: stimulation by acetylcholine, bradykinin and arachidonic acid. $\mathrm{J}$ Pharmacol Exp Ther 237:893-900

29. Jagnandan D, Sessa WC, Fulton D (2005) Intracellular location regulates calcium-calmodulin-dependent activation of organellerestricted eNOS. Am J Physiol Cell Physiol 289:C1024-C1033

30. Kojda G, Harrison D (1999) Interactions between NO and reactive oxygen species: pathophysiological importance in atherosclerosis, hypertension, diabetes and heart failure. Cardiovasc Res 43:562571

31. Konishi M, Su C (1983) Role of endothelium in dilator responses of spontaneously hypertensive rat arteries. Hypertension 5:881886

32. Ku DD (1982) Coronary vascular reactivity after acute myocardial infarction. Science 218:576-578

33. Lamas S, Lowenstein CJ, Michel T (2007) Nitric oxide signaling comes of age: 20 years and thriving. Cardiovasc Res 75:207-209

34. Ledoux J, Taylor MS, Bonev AD, Hannah RM, Solodushko V, Shui B, Tallini Y, Kotlikoff MI, Nelson MT (2008) Functional architecture of inositol 1, 4, 5-trisphosphate signaling in restricted spaces of myoendothelial projections. Proc Natl Acad Sci U S A 105:9627-9632

35. Loot AE, Popp R, Fisslthaler B, Vriens J, Nilius B, Fleming I (2008) Role of cytochrome P450-dependent transient receptor potential V4 activation in flow-induced vasodilatation. Cardiovasc Res 80:445-452

36. Lüscher TF, Vanhoutte PM (1986) Endothelium-dependent contractions to acetylcholine in the aorta of the spontaneously hypertensive rat. Hypertension 8:344-348

37. Lüscher TF, Vanhoutte PM (1990) The endothelium: modulator of cardiovascular function. CRC, Boca Raton

38. Lundberg JO (2006) Nitric oxide metabolites and cardiovascular disease. Markers, mediators, or both? J Am Col Cardiol 47:580 581

39. Marin E, Sessa WC (2007) Role of endothelial-derived nitric oxide in hypertension and renal diseases. Curr Opin Nephrol Hypertens 16:105-110

40. Minshall RD, Sessa WC, Stan RV, Anderson RG, Malik AB (2003) Caveolin regulation of endothelial function. Am J Physiol Lung Cell Mol Physiol 285:L1179-L1183

41. Moncada S, Vane JR (1979) Pharmacology and endogenous roles of prostaglandin endoperoxides, thromboxane A2 and prostacyclin. Pharmacol Rev 30:293-331

42. Murad F, Mitta CK, Arnold WP, Katsuki S, Kimura H (1978) Guanylate cyclase: activation by azide, nitro-compounds, nitric 
oxide and hydroxyl radical an inhibition by haemoglobin and myoglobin. Adv Cycl Nucleotide Res 9:145-158

43. Nilius B, Droogmans G, Wondergem R (2003) Transient receptor potential channels in endothelium: solving the calcium entry puzzle? Endothelium 10:5-15

44. Nilius B, Owsianik G, Voets T, Peters JA (2007) Transient receptor potential cation channels in disease. Physiol Rev 87:165-217

45. Palmer RMJ, Ashton DS, Moncada S (1988) Vascular endothelial cells synthesize nitric oxide from L-arginine. Nature 333:664-666

46. Palmer RMJ, Moncada S (1989) A novel citrulline-forming enzyme implicated in the formation of nitric oxide by vascular endothelial cells. Biochem Biophys Res Commun 158:348-352

47. Radomski MW, Palmer RMJ, Moncada S (1987) The role of nitric oxide and cGMP in platelet adhesion to vascular endothelium. Biochem Biophys Res Commun 148:1482-1489

48. Rees DD, Palmer RMJ, Hodson HF, Moncada S (1989) A specific inhibitor of nitric oxide formation from L-arginine attenuates endothelium-dependent relaxation. Br J Pharmacol 96:418-424

49. Rees DD, Palmer RMJ, Moncada S (1989) The role of endothelium-derived nitric oxide in the regulation of blood pressure. Proc Natl Acad Sci U S A 86:3375-3378

50. Rubanyi GM, Lorenz RR, Vanhoutte PM (1985) Bioassay of endothelium-derived relaxing factor(s). Inactivation by catecholamines. Am J Physiol 249:H95-H101

51. Rubanyi GM, Romero JC, Vanhoutte PM (1986) Flow-induced release of endothelium-derived relaxing factor. Am J Physiol 250: H1145-H1149

52. Rubanyi GM, Vanhoutte PM (1986) Superoxide anions and hyperoxia inactivate endothelium-derived relaxing factor(s). Am J Physiol 250:H822-H827

53. Saliez J, Bouzin C, Rath G, Ghisdal P, Desjardins F, Rezzani R, Rodella LF, Vriens J, Nilius B, Feron O, Balligand JL, Dessy C (2008) Role of caveolar compartmentation in endothelium-derived hyperpolarizing factor-mediated relaxation: $\mathrm{Ca} 2+$ signals and gap junction function are regulated by caveolin in endothelial cells. Circulation 117:1065-1074

54. Sankaranarayanan A, Raman G, Busch C, Schultz T, Zimin PI, Hoyer J, Köhler R, Wulff H (2009) Naphtho[1, 2-d]thiazol-2ylamine (SKA-31), a new activator of $\mathrm{KCa} 2$ and $\mathrm{KCa} 3.1$ potassium channels, potentiates the endothelium-derived hyperpolarizing factor response and lowers blood pressure. Mol Pharmacol 75:281-295
55. Scott-Burden T, Vanhoutte PM (1993) The endothelium as a regulator of vascular smooth muscle proliferation. Circulation 87 : V51-V55

56. Segal SS (2005) Regulation of blood flow in the microcirculation. Microcirculation 12:33-45

57. Tallini YN, Brekke JF, Shui B, Doran R, Hwang SM, Nakai J, Salama G, Segal SS, Kotlikoff MI (2007) Propagated endothelial $\mathrm{Ca} 2+$ waves and arteriolar dilation in vivo: measurements in Cx40BAC GCaMP2 transgenic mice. Circ Res 101:1300-1309

58. Touyz RM (2004) Reactive oxygen species and angiotensin II signaling in vascular cells - implications in cardiovascular disease. Braz J Med Biol Res 37:1263-1273

59. Vanhoutte PM (1998) Endothelial dysfunction and inhibition of converting enzyme. Eur Heart J 19:J7-J15

60. Vanhoutte PM (2010) COX-1 and vascular disease. Clin Pharmacol Ther (in press)

61. Vanhoutte PM (2009) How we learned to say NO. Arterioscler Thromb Vasc Biol 29:1156-1160

62. Vanhoutte PM (2009) Say NO to ET. J Auton Nerv Syst 81:271277

63. Vanhoutte PM, Shimokawa H, Tang EH, Feletou M (2009) Endothelial dysfunction and vascular disease. Acta Physiol 196:193-222

64. Vanhoutte PM, Tang EH (2008) Endothelium-dependent contractions: when a good guy turns bad! J Physiol 586:5295-5304

65. Vriens J, Owsianik G, Fisslthaler B, Suzuki M, Janssens A, Voets T, Morisseau C, Hammock BD, Fleming I, Busse R, Nilius B (2005) Modulation of the $\mathrm{Ca} 2+$ permeable cation channel TRPV4 by cytochrome $\mathrm{P} 450$ epoxygenases in vascular endothelium. Circ Res 97:908-915

66. Wölfle SE, Schmidt VJ, Hoyer J, Köhler R, de Wit C (2009) Prominent role of $\mathrm{KCa} 3.1$ in endothelium-derived hyperpolarizing factor-type dilations and conducted responses in the microcirculation in vivo. Cardiovasc Res 82:476-483

67. Wolin MS (2009) Reactive oxygen species and the control of vascular function. Am J Physiol Heart Circ Physiol 296:H539H549

68. Yu J, deMuinck ED, Zhuang Z, Drinane M, Kauser K, Rubanyi GM, Qian HS, Murata T, Escalante B, Sessa WC (2005) Endothelial nitric oxide synthase is critical for ischemic remodelling, mural cell recruitment, and blood flow reserve. Proc Natl Acad Sci U S A 102:10999-11004 


\section{AUTHOR QUERIES}

\section{AUTHOR PLEASE ANSWER ALL QUERIES.}

Q1. Please check if the authors' affiliations were presented correctly.

Q2. Please check if the publication data of reference item number 60 need to be updated. 